\title{
ALFABETIZAÇÃO CIENTÍFICA NA EDUCAÇÃO INFANTIL: ESTADO DA ARTE DE PUBLICAÇÕES ATUAIS
}

\author{
Scientific Literacy in Early Childhood Education: State of the Art of Current \\ Publications
}

\author{
Lia Heberlê de Almeida Pastorio ${ }^{1}$ \\ Elenize Rangel Nicoletti ${ }^{2}$ \\ José Vicente Lima Robaina ${ }^{3}$
}

\begin{abstract}
Resumo: Este artigo resulta da pesquisa de doutorado em desenvolvimento sobre propostas interdisciplinares para a Educação Infantil (EI) voltadas à promoção da Alfabetização Científica (AC). O objetivo é apresentar o mapeamento de trabalhos produzido sobre os temas, utilizando diferentes descritores e períodos, com consulta ao repositório de trabalhos da Capes, denominado de Biblioteca Digital Brasileira de Teses e Dissertações (BDTD) (2000-2018), aos artigos publicados na revista Ensaio - Pesquisa em Educação em Ciências (Revista Ensaio) (2015-2019) e trabalhos em quatro edições do Encontro Nacional de Pesquisa em Educação em Ciências (ENPEC) (2011-2017). A pesquisa de abordagem bibliográfica selecionou 23 trabalhos, sendo três na BDTD, um na Revista Ensaio e 19 nos anais do ENPEC, evidenciando que as áreas pesquisadas são incipientes nas bases de dados, mas trazem contribuições significativas para a promoção da AC.
\end{abstract}

Palavras-chave: Alfabetização Científica. Educação Infantil. Estado da Arte.

Abstract: This article is the result of a doctoral research under development on interdisciplinary proposals for Early Childhood Education (ECE) aimed at promoting Scientific Literacy (SL). The objective is to present the mapping of works produced on the

\footnotetext{
${ }^{1}$ Mestra e doutoranda em Educação em Ciências pela Universidade Federal do Rio Grande do Sul (UFRGS). Docente da rede pública municipal de São Gabriel/RS. Graduada em Licenciatura Plena em Pedagogia (2010) pela Universidade da Região da Campanha (URCAMP). Especialista em Tecnologias da Informação e da Comunicação Aplicadas à Educação (2012) e em Mídias na Educação (2015) pela Universidade Federal de Santa Maria (UFSM). Integra o Grupo de Pesquisa e Estudos em Educação do Campo e Ciências da Natureza (GPEEC Natureza - UFRGS). ORCID: https://orcid.org/0000-0001-9551-6883. E-mail: lia_ha@hotmail.com.

2 Doutora em Educação em Ciências (2017), Mestra em Educação em Ciências (2013) e Licenciada em Ciências Biológicas (2010) pela Universidade Federal de Santa Maria (UFSM). Professora Adjunta na Universidade Federal do Pampa - Campus Caçapava do Sul (UNIPAMPA). Integra o Grupo de Pesquisa e Estudos em Educação do Campo e Ciências da Natureza (GPEEC Natureza - UFRGS). ORCID: https://orcid.org/0000-0003-0350-0791. E-mail: elenizenicoletti@gmail.com.

${ }^{3}$ Pós-Doutor em Educação e Educação do Campo pela UFRGS (2017). Doutor em Educação pela UNISINOS (2007). Mestre em Educação (1996) e Especialista em Educação Química pela UFRGS (1990). Graduado em Licenciatura Curta em Ciências (1982), Graduado em Licenciatura Plena em Química (1985) e Especialista em Toxicologia Aplicada (1987) pela Pontifícia Universidade Católica do Rio Grande do Sul (PUCRS). Professor Adjunto na Universidade Federal do Rio Grande do Sul (UFRGS - Campus Porto Alegre). Coordenador de área do subprojeto PIBID do Curso de educação do Campo - Ciências da Natureza (UFRGS - Campus Porto Alegre) e coordenador do Grupo de Pesquisa e Estudos em Educação do Campo e Ciências da Natureza (GPEEC Natureza - UFRGS). ORCID: https://orcid.org/0000-0003-3956-8034. E-mail: joserobaina1326@gmail.com.
} 
themes, using different descriptors and periods, consulting the Capes Directory of Open Access Repositories, called the Brazilian Digital Library of Theses and Dissertations (BDTD) (2000-2018), articles published in the periodical Ensaio - Pesquisa em Educação em Ciências (Revista Ensaio) (2015-2019) and presentations in four editions of the National Research Meeting in Education in Sciences (ENPEC) (2011-2017). The research of bibliographic approach selected 23 papers, three of them are from BDTD, one is from Revista Ensaio, and nineteen are from ENPEC studies, showing that the researched areas are incipient in the databases, however they present significant contributions to the promotion of SL.

Keywords: Scientific Literacy. Early Childhood Education. State of the art.

\section{Introdução}

Este artigo resulta de uma pesquisa de doutorado em desenvolvimento. $\mathrm{O}$ foco da pesquisa é investigar o potencial de propostas interdisciplinares na Educação Infantil para a promoção da Alfabetização Científica (AC). O Ensino de Ciências na Educação Infantil é um campo fértil de estudo, com inúmeras possibilidades a serem investigadas e necessidades a serem exploradas. Acredita-se que, quando trabalhado de modo interdisciplinar desde a primeira etapa de ensino, esse ensino possa contribuir para o desenvolvimento dos diferentes níveis de $\mathrm{AC}$, incentivando a criticidade e a autonomia em crianças.

A Educação Infantil encontra-se em processo de consolidação pedagógica, visto que no ano de 2013 a aprovação da Lei n. ${ }^{\circ}$ 12.796/2013 (BRASIL, 2013) oficializou a Emenda Constitucional n. ${ }^{\circ}$ 59/2009 (BRASIL, 2009), instituindo a obrigatoriedade da educação a partir dos 4 anos de idade. Assim, a legislação, por meio da Lei de Diretrizes e Bases (LDB) (BRASIL, 1996), passa a afirmar que a Educação Básica é obrigatória e gratuita dos 4 aos 17 anos de idade, garantindo a gratuidade e a obrigatoriedade da pré-escola às crianças de até 5 anos de idade (BRASIL, 2013).

Dessa forma, o desenvolvimento de atividades na Educação Infantil torna-se um desafio e um campo de experimentação, com experiências que extrapolam o vivido no âmbito familiar. Além disso, gera uma inquietação própria das crianças que naquela faixa etária estão descobrindo o mundo, são curiosas, pois perguntam e interessam-se por saber, são ativas e não conformistas, possuindo uma vivacidade na busca do entendimento ao que está a sua volta.

\footnotetext{
Tem-se a favor dessa tarefa o fato de que os estudantes, especialmente as crianças, são bons pesquisadores, são curiosos, criativos e trabalhadores. Ao se tornar consciente dessas características e valorizá-las, o professor passa a desafiar os alunos e começa também a ser envolvido pelas demandas e questionamentos propostos em aula. A educação em ciências torna-se assim empolgante, dinâmica, estimulante. (PAVÃO, 2006, p. 02).
}

A AC possibilita que o estudante compreenda seu papel cidadão, à medida que incentiva a sua autonomia, possibilitando ao aprendiz o desenvolvimento do pensamento crítico e reflexivo e a responsabilização face a situações concretas. Milaré, Richetti e Alves Filho (2009) reiteram que a AC tem como objetivo permitir que os indivíduos tenham o mínimo de conhecimentos científicos necessários para o exercício da cidadania. 
Diferentes autores ressaltam que essa formação de sujeitos para a compreensão das relações entre Ciência, Tecnologia e Sociedade ${ }^{4}$ é um processo que precisa ser iniciado desde os primeiros anos da escolarização (LORENZETTI; DELIZOICOV, 2001; TENREIRO-VIEIRA; VIEIRA, 2011). Marques e Marandino (2018) também defendem que a $\mathrm{AC}$ deve iniciar na infância e que a Educação Infantil precisa de um olhar atento às suas especificidades por todos os envolvidos no processo de formação dessas crianças:

[...] mudanças nas concepções de criança e de infância também contribuem para que seja revista a proposta pedagógica da educação infantil, superando-se o modelo de preparação para o ensino fundamental e considerando-se a importância de valorizar a infância e seus modos próprios de ser e estar no mundo, bem como a criança como produtora de cultura. Nessa ideia pensar na proposta da Educação Infantil é um desafio, sendo que a intenção desse nível, "considera a criança e as infâncias como centro do processo e promova a superação de uma pedagogia tradicional que tem como foco a transmissão de conteúdos fragmentados, [...] acaba por significar o esvaziamento do debate acerca do trabalho. (MARQUES; MARANDINO, 2018, p. 9).

Na sequência, as autoras defendem que "os conhecimentos do campo científico podem estar presentes nas experiências de aprendizagem possibilitadas às crianças de maneira integrada, participativa e lúdica, como um elemento da cultura mais ampla na qual a criança se insere" (MARQUES; MARANDINO, 2018, p. 10). O Ensino de Ciências na Educação Infantil deve respeitar as peculiaridades dessa etapa, evitando processos de conceitualização formal. As ações educativas devem ser flexíveis e adaptáveis, de acordo com o nível de desenvolvimento e maturidade dos alunos.

Faz-se necessário, portanto, considerar as especificidades da criança pequena, considerando suas formas próprias de pensar, interagir, ser e estar no mundo, suas lógicas (nas quais fantasia e realidade se fazem presentes de maneira não contraditória) e suas necessidades (que vão além da cognição). (MARQUES; MARANDINO, 2018, p. 10).

Nesse processo, o professor deve elaborar e desenvolver ações educativas consistentes, criando e recriando possibilidades para que o aluno desenvolva novas aprendizagens (CARVALHO, 2012). Sasseron e Carvalho (2008, p. 333) propõem que a AC deve ser mediada por "[...] um ensino de ciências que leve os alunos a trabalhar e discutir problemas envolvendo fenômenos naturais e as implicações que o conhecimento destes pode acarretar à sociedade e ao meio ambiente". Salienta-se que as crianças se inserem de uma forma concreta na sociedade, uma vez que são agentes transformadores de realidades. Desse modo, são capazes de envolver a sua família e a comunidade nos processos educativos, compartilhando responsabilidades, pedindo ajuda e cobrando os adultos por ações conscientes, ou seja, atuam como disseminadores de saberes.

\footnotetext{
${ }^{4} \mathrm{Na}$ literatura, encontramos o uso da letra A ao final da sigla CTS, como forma de acentuar a importância das relações ambientais dentro do enfoque CTS, formando o acrônimo CTSA (Ciência, Tecnologia, Sociedade e Ambiente). Entretanto, optou-se por usar apenas a sigla CTS, pois entendemos que as relações ambientais são intrínsecas ao desenvolvimento científico e tecnológico, ou seja, no sentido teórico, o uso de uma ou outra sigla não representa abordagens diferentes. Por esse motivo, utilizamos a sigla original CTS.
} 
Nesse envolvimento ativo, as crianças são protagonistas de sua aprendizagem. Segundo Schneider (2015, p. 45): "Quando a escola reconhecer o Protagonismo Infantil, latente e pulsante, talvez descubra uma leveza maior no processo de ensinar e de aprender, encontrando a recíproca necessária para a garantia de autonomia e participação de todos os atores".

Dessa forma, o protagonismo e a autonomia desenvolvidos nesse processo são características importantes para o desenvolvimento da $\mathrm{AC}$, uma vez que se propõe a preparar os estudantes para o posicionamento crítico, na tomada de decisões e ações conscientes. Essa é uma perspectiva importante para pensar e fazer a Educação Infantil, trazendo novas possibilidades no processo de consolidação dessa etapa no cenário nacional de educação.

Apesar da relevância da educação científica em todas as etapas da Educação Básica, ainda são muito restritas as pesquisas direcionadas à Educação Infantil no conjunto da produção brasileira na área de Educação em Ciências. As pesquisas nessa área vêm crescendo tanto em teses e dissertações quanto em artigos e anais de eventos da área. Entretanto, tais estudos ainda são predominantes para o Ensino Médio. Segundo Megid Neto (2014), a produção acadêmica na área de ensino de ciências entre 1972 (primeira defesa na área) e 2010 foi de 3.882 teses e dissertações. Seu estudo apontou que, em relação ao nível escolar desses trabalhos, 53\% das pesquisas são voltadas para o Ensino Médio, 28\% para o Ensino Superior, 18,5\% para o Ensino Fundamental e apenas 0,5\% para a Educação Infantil, nosso foco de análise.

Nessa perspectiva, este estudo justifica-se por buscar conhecer as publicações produzidas, em termos de teses, dissertações e artigos, sobre essa etapa educacional e por considerar a criança como sujeito do processo de $\mathrm{AC}$, atentando às especificidades da infância.

A partir desses pressupostos, elencou-se como objetivo identificar e analisar a produção acadêmica (teses, dissertações e artigos) voltada para AC na Educação Infantil, traçando um panorama desses trabalhos. Organizou-se um estudo abrangendo de forma específica a produção acadêmica sobre $\mathrm{AC}$ na Educação Infantil para responder à seguinte questão: o que se pesquisa sobre AC na Educação Infantil?

\section{Articulações entre Alfabetização Científica e Ilhas Interdisciplinares de Racionalidade}

O debate sobre AC envolve diferentes definições e pretensões. Laugksch (2000 apud MARQUES; MARANDINO, 2019) chama a atenção de que não é possível construir uma definição única e permanente, pois o conceito de $\mathrm{AC}$ possui diferentes significados e interpretações que variam de acordo com o contexto. Na literatura nacional, por exemplo, há uma diversidade de terminologias que os autores utilizam: "Alfabetização Científica" (AULER; DELIZOICOV, 2001; BRANDI; GURGEL, 2002; CHASSOT, 2000; LORENZETTI; DELIZOICOV, 2001); "Letramento Científico" (MAMEDE; ZIMMERMANN, 2005; SANTOS; MORTIMER, 2001), e há ainda os que utilizam "Enculturação Científica" (CARVALHO; TINOCO, 2006; MORTIMER; MACHADO, 1996).

$\mathrm{O}$ debate que envolve essas terminologias trata das preocupações com a abordagem do Ensino de Ciências para o desenvolvimento de soluções práticas à sociedade, ao meio ambiente e às pessoas. Para o conceito de "Enculturação Científica", os autores consideram que os alunos devem possuir a cultura científica como algo natural em seu contexto, que resultará em participações em discussões sobre assuntos científicos (SASSERON; CARVALHO, 2011). 
O "Letramento Científico" assemelha-se ao processo de letramento escolar, como define Soares (1998, p. 18), ao falar de "Letramento" como "resultado da ação de ensinar ou aprender a ler e escrever", e Kleiman (1995, p. 19), que designa como "conjunto de práticas sociais que usam a escrita enquanto sistema simbólico e enquanto tecnologia".

Para explicitar o conceito de "Alfabetização Científica", nos reportamos ao pensamento de Lorenzetti (2000, p. 78), que a defende como:

[...] o processo pelo qual a linguagem das Ciências Naturais adquire significados, constituindo-se um meio para o indivíduo ampliar o seu universo de conhecimento, a sua cultura, como cidadão inserido na sociedade. Estes conhecimentos adquiridos serão fundamentais para a sua ação na sociedade, auxiliando-o nas tomadas de decisões que envolvam o conhecimento científico.

Nesse sentido, a compreensão da presente pesquisa fundamenta-se à luz do pensamento de Lorenzetti (2000) para as discussões que envolvem o conceito de sujeito alfabetizado cientificamente, utilizando-se da terminologia "Alfabetização Científica".

Considerando que a $\mathrm{AC}$ é um processo que deve iniciar na infância e permanecer ao longo da vida, diferentes recursos didáticos podem ser utilizados para a sua promoção, assim como se faz necessário relacioná-los a metodologias de ensino. Nesse viés, surgem diversas possibilidades, tais como: Ensino de Ciências por Investigação (CARVALHO, 2012); os Três Momentos Pedagógicos (DELIZOICOV; ANGOTTI; PERNAMBUCO, 2011); e as Ilhas Interdisciplinares de Racionalidade (FOUREZ, 1997). Neste texto, evidencia-se o uso dos termos Alfabetização Científica e Ilhas Interdisciplinares de Racionalidade (IIR), pois são os objetos de estudo da tese de doutorado ao qual este trabalho faz parte.

A metodologia das IIR foi desenvolvida pelo educador Gérard Fourez, que valorizava a importância da interdisciplinaridade no processo de aprendizagem para a formação de um sujeito crítico. Entre as publicações internacionais na área de Ensino de Ciências, o autor está entre os quatro teóricos mais citados sobre o tema, sendo o segundo mais citado quando o assunto é epistemologia da interdisciplinaridade (MOZENA; OSTERMANN, 2014).

Fourez defende a interdisciplinaridade como uma prática que busca resoluções em diversos aspectos para os problemas do cotidiano (BETTANIN, 2003). Nessa perspectiva, o autor propôs a metodologia de IIR, cuja base epistemológica é a AC. O objetivo dessa metodologia é proporcionar a participação ativa dos alunos no processo, na intenção de desenvolver habilidades de comunicação e ação sobre o assunto, articulando o conhecimento cotidiano do indivíduo com o conhecimento científico. Dessa maneira, Fourez (1997) argumenta que se deve desenvolver um ensino científico que permita a autonomia do sujeito, possibilitando o domínio e a comunicação das tecnologias intelectuais.

Assim, é possível observar que a AC aponta para o desenvolvimento da consciência crítica no sentido de interferir na sociedade para transformá-la, bases que sustentam a educação CTS (Ciência, Tecnologia e Sociedade). Em suma, esse conceito envolve discussões que abrangem a comunidade científica, a comunidade escolar e os profissionais de comunicação acerca do que o cidadão sabe e deveria saber sobre as relações entre Ciência, Tecnologia e Sociedade (LEAL; GOUVÊA, 2000).

Consideramos fundamental a compreensão das influências que a Ciência e a Tecnologia têm na Sociedade, uma vez que impactam diretamente as relações familiares, sociais e o mundo do trabalho. Hazen e Trefil (1995, p. 11-12) complementam que "ser capaz 
de entender tais debates é hoje tão importante quanto saber ler e escrever. Logo, é preciso ser alfabetizado em ciências".

Lorenzetti (2020, p. 11) reitera

Assim, os indivíduos passam a utilizar o conhecimento científico em suas vidas, discutindo suas implicações sociais, econômicas e políticas, tendo em vista que, em uma sociedade democrática, o nível de alfabetização científica da população tem impacto importante para as decisões de políticas de ciência e de tecnologia.

Neste sentido, percebemos a relevância da AC para a compreensão dessas relações de CTS em direção à participação informada e inteligente em assuntos que envolvem política, ciência e tecnologia. Fourez (1997, p. 121) complementa: "o que deve ser objeto de uma alfabetização científica e técnica não é, então, uma série de conhecimentos particulares precisos, mas um conjunto global que permita (ao indivíduo) orientar-se e compreender-se no nosso universo". Dessa forma, a AC é um caminho pedagógico para evitar a fragmentação do conhecimento, para abordar o Ensino de Ciências e possibilitar que os conceitos e conteúdos disciplinares sejam tratados de forma interdisciplinar, instrumentalizando os alunos científica e tecnologicamente, para a tomada de decisões e ações conscientes.

\section{Metodologia}

Este trabalho caracteriza-se como uma pesquisa do tipo "estado da arte" e inspira-se na metodologia do trabalho de Viecheneski, Lorenzetti e Carletto (2015). Trata-se de um estudo teórico, que se constitui em uma revisão das pesquisas acadêmicas sobre o tema, sendo denominado "estado da arte" por Romanowski e Ens (2006). Engloba o estudo de teses e dissertações, produções de congressos na área e publicações em periódicos, diferenciando-se de "estado do conhecimento". Para realizar uma pesquisa do tipo "estado da arte",

[...] não basta apenas estudar os resumos de dissertações e teses, são necessários estudos sobre as produções em congressos na área, estudos sobre as publicações em periódicos na área. $\mathrm{O}$ estudo que aborda apenas um setor das publicações sobre o tema estudado vem sendo denominado de "estado do conhecimento". (ROMANOWSKI; ENS, 2006, p. 39-40).

Para Fernandes e Megid Neto (2015, p. 546), trata-se de "um inventário descritivo-analítico e avaliativo da produção em determinado campo de conhecimento". Nessa perspectiva, Ferreira (2002, p. 258) afirma que essas pesquisas são:

definidas como de caráter bibliográfico, elas parecem trazer em comum o desafio de mapear e de discutir uma certa produção acadêmica em diferentes campos do conhecimento, tentando responder que aspectos e dimensões vêm sendo destacados e privilegiados em diferentes épocas e lugares, de que formas e em que condições têm sido produzidas certas dissertações de mestrado, teses de doutorado, publicações em periódicos e comunicações em anais de congressos e de seminários. (FERREIRA, 2002, p. 258). 
A presente pesquisa aborda um estudo mais panorâmico e descritivo da produção direcionada à $\mathrm{AC}$ na Educação Infantil. A pesquisa investigou as dissertações e teses armazenadas na Biblioteca Digital Brasileira de Teses e Dissertações (BDTD) (BIBLIOTECA..., 2019), delimitando-se o período de um triênio (2016-2018) para os descritores "Educação Infantil", "Interdisciplinaridade" e "Ensino de Ciências". O tempo delimitado deu-se em função de os termos abrangerem uma etapa da Educação Básica, um campo de pesquisa e uma área de ensino, respectivamente, e compreenderem um alto número de pesquisas. Para complementar as buscas, foram elencados os descritores "Alfabetização Científica" e "Ilhas Interdisciplinares de Racionalidade (IIR)", dessa vez abrangendo um período de 18 anos (de 2000 a 2018), considerando que a AC é o foco deste trabalho e que as IIR são uma metodologia baseada em projetos, que tem como eixo central a AC.

Nos artigos divulgados na revista Ensaio Pesquisa em Educação em Ciências (Revista Ensaio) (ENSAIO..., 2019), foram analisados nove volumes do período de 2015 a 2019. Em relação aos trabalhos completos apresentados no Encontro Nacional de Pesquisa em Educação em Ciências (ENPEC) (ENCONTRO..., 2019), analisaram-se quatros edições, compreendendo o período de 2011 a 2017.

Para fins de análise desses trabalhos, utilizaremos o conceito de Análise de Conteúdo de Bardin (2011), pois foram eleitas categorias pré-estabelecidas, definidas como "Alfabetização Científica na Educação Infantil" (identificando o problema de pesquisa e a metodologia utilizada pelos autores) e "Propostas de Promoção de AC".

Para Bardin (2011), o termo Análise de Conteúdo pode ser considerado como:

[...] um conjunto de técnicas de análise das comunicações visando a obter, por procedimentos sistemáticos e objetivos de descrição do conteúdo das mensagens, indicadores (quantitativos ou não) que permitam a inferência de conhecimentos relativos às condições de produção/recepção (variáveis inferidas) destas mensagens (BARDIN, 2011, p. 47).

O texto foi organizado em seis seções: na primeira apresenta-se a metodologia do trabalho. Na segunda, o panorama das produções na BDTD conforme descritores e períodos específicos elencados para a pesquisa. Na terceira, apresentam-se os trabalhos do ENPEC e as publicações da Revista Ensaio, analisando-se os trabalhos com base em períodos e descritores específicos. A seguir, na quarta e na quinta seção apresenta-se uma breve caracterização dos 19 trabalhos selecionados, identificando tendências, localizando lacunas e mapeando a produção da área utilizando a análise de conteúdo de Bardin (2011). Na quarta seção, são identificados o problema de pesquisa e a metodologia utilizada pelos autores nos trabalhos selecionados. Na quinta seção, disserta-se sobre as Propostas de promoção de AC. Por último, apresentamos as considerações finais.

\section{Resultados}

4.1 Panorama das produções na Biblioteca Digital Brasileira de Teses e Dissertações (BDTD)

Para delimitar a pesquisa do mapeamento das dissertações e teses produzidas no Brasil, foram utilizadas as informações da BDTD. O Instituto Brasileiro de Informação em Ciência e Tecnologia (IBICT) desenvolveu e coordena a BDTD, que é mantida por meio das informações que as instituições brasileiras de ensino e pesquisa fornecem. A BDTD, com a 
colaboração dessas instituições, "possibilita que a comunidade brasileira de C\&T (Ciência e Tecnologia) publique e difunda suas teses e dissertações produzidas no País e no exterior, dando maior visibilidade à produção científica nacional” (BIBLIOTECA..., 2019).

Assim, a ferramenta permite a pesquisa por título, autor, assunto, resumo, editor, ano de defesa e a pesquisa em todos os campos. Ao pesquisar por um ou mais descritores, a plataforma apresenta todas as produções existentes conforme a seleção indicada pelo pesquisador.

Ao todo foram analisados 872 trabalhos, dos quais apenas três contemplavam a "Alfabetização Científica" envolvendo crianças ou direcionadas à Educação Infantil, conforme observa-se na Tabela 1.

Em um primeiro momento, foi pesquisado o descritor "Alfabetização Científica" nos títulos e nos resumos das teses e dissertações dos anos de 2000 a 2018. Salienta-se que o critério utilizado para seleção de trabalhos era a etapa da Educação Básica atendida na pesquisa, nesse caso, nosso interesse era os trabalhos direcionados à Educação Infantil. Nessa busca, foram encontrados 79 trabalhos, mas apenas uma dissertação relacionada ao nosso objeto de estudo defendida no ano de 2017 na Universidade Regional de Blumenau (FURB). Do total de trabalhos analisados, 70 eram de mestrado e apenas nove de doutorado.

Tabela 1 - Pesquisas sobre Alfabetização Científica na Educação Infantil realizadas no Brasil durante o período de 2000 a 2018 e nos anos de 2016 a 2018

\begin{tabular}{|c|c|c|c|c|c|c|}
\hline \multicolumn{7}{|c|}{ BDTD } \\
\hline DESCRITORES & $\begin{array}{l}\text { CAMPO } \\
\text { PESQUIS } \\
\text { ADO } \\
\end{array}$ & ANO & $\begin{array}{c}\text { TOTAL DE } \\
\text { TRABALHOS }\end{array}$ & $\begin{array}{l}\text { TRABALHOS } \\
\text { SELECIONADOS }\end{array}$ & TIPO & $\begin{array}{l}\mathrm{N}^{\circ} \\
\text { de } \\
\text { IES }\end{array}$ \\
\hline $\begin{array}{c}\text { Alfabetização } \\
\text { Científica }\end{array}$ & Título & $2000 / 2018$ & 79 & 1 & $\mathrm{D}$ & 24 \\
\hline Ensino de Ciências & Título & $2016 / 2018$ & 286 & 0 & - & 42 \\
\hline Educação Infantil & Título & $2016 / 2018$ & 390 & 2 & $\mathrm{~T}-\mathrm{D}$ & 50 \\
\hline Interdisciplinaridade & Título & $2016 / 2018$ & 76 & 0 & & 30 \\
\hline $\begin{array}{c}\text { Ilhas } \\
\text { Interdisciplinares de } \\
\text { Racionalidade }\end{array}$ & $\begin{array}{l}\text { Todos os } \\
\text { campos }\end{array}$ & $2000 / 2018$ & 14 & 0 & - & 08 \\
\hline $\begin{array}{c}\text { Ilhas de } \\
\text { Racionalidade }\end{array}$ & $\begin{array}{l}\text { Todos os } \\
\text { campos }\end{array}$ & $2000 / 2018$ & 27 & 0 & - & 08 \\
\hline \multicolumn{3}{|c|}{ Total de trabalhos analisados } & \multicolumn{4}{|c|}{872} \\
\hline \multicolumn{3}{|c|}{ Total de trabalhos selecionados } & \multicolumn{4}{|c|}{03} \\
\hline
\end{tabular}

Legenda: IES: Instituição de Ensino Superior.

Fonte: Elaborada pelos autores com base nos dados fornecidos pela homepage da Coordenação de Aperfeiçoamento de Pessoal de Nível Superior (CAPES), 2021.

Quanto aos demais trabalhos para esse descritor, localizamos trabalhos em 24 instituições diferentes, sendo 20 universidades públicas e quatro universidades privadas. A Universidade de São Paulo (USP) foi a instituição com maior representação, com 14 trabalhos, seguida da FURB com oito trabalhos e a Universidade Federal de Santa Catarina (UFSC) com seis trabalhos. As demais instituições tiveram uma representação igual ou inferior a cinco:

a) Universidade Federal de São Carlos (UFSCar), Universidade Estadual Paulista (UNESP) e Universidade Federal de Itajubá (UNIFEI), com cinco trabalhos; 
b) Universidade Federal do Ceará (UFC), Universidade Federal de Pernambuco (UFPE) e Universidade Federal de Sergipe (UFS), com quatro trabalhos;

c) Pontifícia Universidade Católica de São Paulo (PUC-SP), Universidade Federal do ABC (UFABC) e Universidade Federal de Alagoas (UFAL), com três trabalhos;

d) Universidade de Caxias do Sul (UCS), Universidade Federal do Espírito Santo (UFES), Universidade Federal Fluminense (UFF) e Universidade Federal de Goiás (UFG), com dois trabalhos; e, por fim,

e) Universidade Estadual da Paraíba (UEPB), Universidade Federal de Ouro Preto (UFOP), Universidade Federal de Pelotas (UFPel), Universidade Federal do Rio Grande do Sul (UFRGS), Universidade Estadual de Campinas (UNICAMP), Universidade Estadual do Oeste do Paraná (UNIOESTE), Universidade do Vale do Rio dos Sinos (UNISINOS) e Universidade do Vale do Taquari (UNIVATES), com representação de apenas um trabalho cada uma delas.

Sobre a etapa de pesquisa envolvida, a maioria eram direcionados ao Ensino Médio, sendo 24 trabalhos. Em seguida, aparecem os trabalhos direcionados aos Anos Iniciais, sendo 11 trabalhos; as pesquisas com professores aparecem com 10 trabalhos e as pesquisas com alunos dos anos finais do Ensino Fundamental foram de nove trabalhos. As pesquisas de Educação Não Formal tiveram uma representação de seis trabalhos; as pesquisas no Ensino Superior estiveram presentes em cinco trabalhos. As demais pesquisas tiveram uma representação inferior a cinco trabalhos, sendo que três pesquisas envolviam a análise de materiais e livros didáticos; duas eram direcionadas aos alunos da Educação de Jovens e Adultos (EJA); duas investigavam as feiras de ciências (alunos, professores e coordenadores); duas bibliográficas; uma documental; uma envolvendo o Ensino Técnico e uma investigando o Programa Mais Educação (PME). Vale salientar que um trabalho foi descartado, pois, apesar de ter sido localizado pelo descritor, se referia à alfabetização no contexto da leitura e escrita, diferente de nosso foco de estudo, que é a AC.

Em um segundo momento, foi pesquisado o descritor "Educação Infantil" nos títulos das teses e dissertações dos anos de 2016 a 2018, buscando localizar os termos "Alfabetização Científica" ou "Educação Científica". Foram encontrados 390 trabalhos e, dentre eles, apenas dois foram selecionados, sendo uma tese (MENEZES, 2016) da Universidade Federal da Bahia (UFBA) e uma dissertação (SILVA, 2016) da USP, ambas defendidas no ano de 2016.

Quando pesquisado o descritor "Alfabetização Científica" nos títulos das teses e dissertações dos anos de 2000 a 2018, foram encontrados 79 trabalhos e foi selecionado apenas um em que constava o termo "Educação Infantil": uma dissertação (CARDOSO, 2017) defendida na FURB.

Posteriormente, foram pesquisados os descritores: "Ensino de Ciências", "Interdisciplinaridade", "Ilhas Interdisciplinares de Racionalidade" e "Ilhas de Racionalidade". Nessa busca utilizou-se o mesmo critério para trabalhos alusivos à Alfabetização Científica e Educação Infantil. Porém, não foram encontrados trabalhos relativos ao nosso objeto de pesquisa. Vale destacar que, para os descritores "Ilhas Interdisciplinares de Racionalidade" e "Ilhas de Racionalidade", analisaram-se também os resumos, destacando-se que a maior parte dos trabalhos eram direcionados aos Anos Finais e ao Ensino Médio.

Quando pesquisamos o descritor "Ilhas Interdisciplinares de Racionalidade" no período de 2000 a 2018, na busca em "Todos os campos", localizamos apenas 14 trabalhos em oito instituições diferentes, sendo sete em universidades públicas e sete em instituições privadas. A FURB foi a universidade com maior representação, com quatro trabalhos. Em 
seguida, aparecem a UFSC com três trabalhos, a UCS com dois trabalhos, e as demais com apenas um trabalho, são elas: Pontifícia Universidade Católica do Rio Grande do Sul (PUCRS), Universidade Federal do Pará (UFPA), UFRGS, UNESP e USP. Desses trabalhos, 13 eram dissertações e apenas um era tese.

Quando pesquisamos o descritor "Ilhas de Racionalidade" em "Todos os campos" no mesmo período, foram encontrados e analisados 21 trabalhos. Desses, cinco eram de outras áreas do conhecimento que não faziam parte da área da educação. Como 13 trabalhos se repetiram da busca do descritor anterior e três trabalhos foram encontrados com esse filtro (três dissertações de universidades públicas distintas (UFRGS, UFSC e UFPE)), 16 trabalhos foram encontrados no total referentes a "Ilhas de Racionalidade". No entanto, nenhum deles fazia parte do escopo da nossa pesquisa.

Destaca-se que, entre esses 16 trabalhos analisados, oito eram direcionados para o Ensino Médio, três para Anos Finais do Ensino Fundamental, dois com alunos da Educação de Jovens e Adultos (EJA), um para Anos Iniciais do Ensino Fundamental (5 ano), um com discentes de um Programa de Pós-graduação e por fim um direcionado à formação de professores.

4.2 Panorama dos trabalhos apresentados no ENPEC e produções publicadas na Revista Ensaio

Para delimitar a pesquisa, três áreas de análise foram escolhidas, de acordo com as linhas temáticas disponíveis nos anais do evento, sendo elas: i) Ensino e aprendizagem de conceitos científicos 1 e 2; ii) Educação em espaços não formais e divulgação científica; e iii) Alfabetização Científica e tecnológica, abordagens CTS/CTSA.

Para a seleção de trabalhos, foi realizada uma leitura cuidadosa dos títulos de cada comunicação oral e foram identificados os trabalhos que continham um ou mais dos descritores ("Alfabetização Científica", "Educação Científica", "Educação Infantil", "pré-escola", "criança" e "Ciência") e que estivessem relacionados ao objeto de nosso estudo.

Como mostra a Tabela 2, foram analisados 1354 trabalhos e selecionados 16, sendo: um apresentado no VIII ENPEC (realizado em 2011), dois apresentados no IX ENPEC (realizado em 2013), nove artigos apresentados no X ENPEC (realizado em 2015) e sete apresentados no XI ENPEC (realizado em 2017).

Tabela 2 - Pesquisas sobre Alfabetização Científica na Educação Infantil nas atas do ENPEC

\begin{tabular}{l|ccccc|cccc}
\hline \multicolumn{1}{c|}{ ENPEC } \\
\hline \multicolumn{1}{c}{ Áreas analisadas } & \multicolumn{3}{c|}{ Total de trabalhos analisados } & \multicolumn{3}{c}{ Total de trabalhos selecionados } \\
\cline { 2 - 9 } & 2011 & 2013 & 2015 & 2017 & 2011 & 2013 & 2015 & 2017 \\
\hline $\begin{array}{l}\text { 01. Ensino e aprendizagem de } \\
\text { conceitos científicos 15 }\end{array}$ & 184 & 136 & 204 & 216 & 00 & 00 & 03 & 03 \\
$\begin{array}{l}\text { 04. Educação em espaços não } \\
\text { formais e divulgação científica }\end{array}$ & 72 & 57 & 69 & 103 & 01 & 00 & 00 & 01 \\
$\begin{array}{l}\text { 09. Alfabetização Científica e } \\
\text { tecnológica, abordagens CTS e } \\
\text { ensino de ciências }\end{array}$ & 80 & 63 & 60 & 110 & 00 & 02 & 00 & 02 \\
\hline
\end{tabular}

Fonte: Elaborada pelos autores com base nos dados fornecidos pela homepage do ENPEC, 2021.

\footnotetext{
${ }^{5}$ Nos anos de 2013 e 2015, devido à demanda de trabalhos, a organização do evento dividiu as publicações em dois grupos (Ensino e aprendizagem de conceitos científicos 1 e 2). No ano de 2013, o grupo 1 teve 72 trabalhos e o grupo 2, 64 trabalhos. Em 2015, o grupo 1 teve 95 trabalhos e o grupo 2 com 109.
} 
$\mathrm{Na}$ Revista Ensaio, encontrou-se apenas um artigo direcionado a Alfabetização Científica e a criança na edição de 2019 no volume 21 . Nesse trabalho, as autoras analisam o potencial de uma brinquedoteca para a promoção da AC de crianças. O Quadro 1 apresenta a lista dos artigos encontrados e analisados.

Quadro 1 - Relação dos artigos encontrados na BDTD, ENPEC e Revista Ensaio

\begin{tabular}{|c|c|c|c|c|c|}
\hline \multicolumn{6}{|c|}{ BDTD } \\
\hline $\mathbf{N}^{\mathbf{o}}$ & Autor & Título do trabalho & $\begin{array}{l}\text { IES envolvida } \\
\text { no estudo }\end{array}$ & Tipo & Ano \\
\hline 1 & $\begin{array}{l}\text { CARDOSO, R. A. } \\
\text { P. }\end{array}$ & $\begin{array}{l}\text { Alfabetização científica na pré-escola: } \\
\text { ações em busca de transformações } \\
\text { para uma educação sustentável }\end{array}$ & FURB & $\mathrm{D}$ & 2017 \\
\hline 2 & $\begin{array}{l}\text { MENEZES, M. C. } \\
\text { F. }\end{array}$ & $\begin{array}{l}\text { Um diálogo entre a pedagogia } \\
\text { freireana e a educação científica na } \\
\text { educação infantil. }\end{array}$ & UFBA & $\mathrm{T}$ & 2016 \\
\hline 3 & SILVA, T. P. & $\begin{array}{l}\text { Mamãe galinha, menina joaninha: } \\
\text { representações dos animais no livro } \\
\text { infantil e suas possibilidades na } \\
\text { educação científica. }\end{array}$ & USP & $\mathrm{D}$ & 2016 \\
\hline \multicolumn{6}{|c|}{ ENPEC } \\
\hline $\mathbf{N}^{\mathbf{0}}$ & Autor(es) & Título do trabalho & $\begin{array}{c}\text { IES envolvida } \\
\text { no estudo }\end{array}$ & Tipo & Ano \\
\hline 1 & $\begin{array}{l}\text { LEPORO, N.; } \\
\text { DOMINGUEZ, C. } \\
\text { R. C. }\end{array}$ & $\begin{array}{l}\text { Alfabetização científica na educação } \\
\text { infantil: quando os pequenos visitam o } \\
\text { museu de ciências. }\end{array}$ & USP & $\mathrm{TC}$ & 2011 \\
\hline 2 & $\begin{array}{l}\text { FAGIONATO-RUF } \\
\text { FINO, S.; } \\
\text { PIERSON, A. H. C. }\end{array}$ & $\begin{array}{l}\text { Cientista tem o cabelo arrepiado, } \\
\text { constrói robôs e polvos gigantes - } \\
\text { ideias de crianças de } 5 \text { e } 6 \text { anos sobre } \\
\text { a ciência e o trabalho do cientista. }\end{array}$ & UFSCar & $\mathrm{TC}$ & 2013 \\
\hline 3 & $\begin{array}{l}\text { MAURENTE, V. M. } \\
\text { M.; } \\
\text { PORCIÚNCULA, } \\
\text { L. O. }\end{array}$ & $\begin{array}{l}\text { Um mergulho pelas atas do ENPEC: } \\
\text { indo ao encontro da ciência na } \\
\text { educação infantil e nos anos iniciais. }\end{array}$ & UFRGS & $\mathrm{TC}$ & 2013 \\
\hline 4 & $\begin{array}{l}\text { LIMA E SILVA, V. } \\
\text { M.; CAPECCHI, M. } \\
\text { C. V. M. }\end{array}$ & $\begin{array}{l}\text { Ciências na Educação Infantil: uma } \\
\text { abordagem investigativa para } \\
\text { brincadeira com bolinhas de sabão. }\end{array}$ & UFABC & $\mathrm{TC}$ & 2015 \\
\hline 5 & $\begin{array}{l}\text { REIS, A. C.; } \\
\text { JANNUZZI , C. M. } \\
\text { L. }\end{array}$ & $\begin{array}{l}\text { Ensino de ciências para professores da } \\
\text { educação infantil. }\end{array}$ & UFF & $\mathrm{TC}$ & 2015 \\
\hline 6 & $\begin{array}{l}\text { ALENCAR, R. N. } \\
\text { B.; TERÁN, A. F.; } \\
\text { BARBOSA, I. S. }\end{array}$ & $\begin{array}{l}\text { O processo de aprendizagem das } \\
\text { crianças da pré-escola usando o } \\
\text { "Peixe-boi-da-Amazônia" (Trichechus } \\
\text { inunguis). }\end{array}$ & $\begin{array}{l}\text { Universidade do } \\
\text { Estado do } \\
\text { Amazonas } \\
\text { (UEA) }\end{array}$ & $\mathrm{TC}$ & 2015 \\
\hline 7 & $\begin{array}{l}\text { PEREIRA, A. F.; } \\
\text { GOULART, M. I. } \\
\text { M.; COUTINHO, F. } \\
\text { A. }\end{array}$ & $\begin{array}{l}\text { Aprendizagem de ciências na } \\
\text { educação infantil } \\
\text { participação em um campo de prática. } \\
\text { Primeiras aproximações. }\end{array}$ & $\begin{array}{l}\text { Universidade } \\
\text { Federal de } \\
\text { Minas Gerais } \\
\text { (UFMG) }\end{array}$ & $\mathrm{TC}$ & 2015 \\
\hline 8 & $\begin{array}{l}\text { PAIXÃO, F. J. ; } \\
\text { MANDAJI, K. C; } \\
\text { MEGID NETO, J. }\end{array}$ & $\begin{array}{l}\text { Brincando com a luz: Ciência na } \\
\text { pré-escola. }\end{array}$ & UNICAMP & $\mathrm{TC}$ & 2015 \\
\hline 9 & $\begin{array}{l}\text { MARQUES, A. C. } \\
\text { T. L. }\end{array}$ & $\begin{array}{l}\text { Ciências na Educação Infantil: uma } \\
\text { reflexão a partir do trabalho com } \\
\text { projetos. }\end{array}$ & USP & $\mathrm{TC}$ & 2015 \\
\hline 10 & $\begin{array}{l}\text { SCHNEIDER, M. } \\
\text { C.; DUARTE, M. } \\
\text { C.; SILVA, L. H. A. }\end{array}$ & $\begin{array}{l}\text { Ciências na } \begin{array}{l}\text { Educação Infantil: } \\
\text { explorando a flutuabilidade na } \\
\text { Pré-escola. }\end{array} \\
\end{array}$ & $\begin{array}{l}\text { Universidade } \\
\text { Federal da } \\
\text { Grande }\end{array}$ & $\mathrm{TC}$ & 2017 \\
\hline
\end{tabular}




\begin{tabular}{|c|c|c|c|c|c|}
\hline & & & $\begin{array}{l}\text { Dourados } \\
\text { (UFGD) }\end{array}$ & & \\
\hline 11 & $\begin{array}{l}\text { AMOÊDO, F. K. F., } \\
\text { SOUZA, J. C. R. }\end{array}$ & $\begin{array}{l}\text { Educação infantil e o diálogo de } \\
\text { comunicar ciências às crianças surdas } \\
\text { na cidade de Parintins-AM. }\end{array}$ & UEA & $\mathrm{TC}$ & 2017 \\
\hline 12 & $\begin{array}{l}\text { MORAES, T. S. V. } \\
\text { et al. }\end{array}$ & $\begin{array}{l}\text { O desenvolvimento de ações de } \\
\text { Investigação Científica com crianças } \\
\text { da Educação Infantil. }\end{array}$ & UNESP & $\mathrm{TC}$ & 2017 \\
\hline 13 & $\begin{array}{l}\text { FREITAS, A. C. S.; } \\
\text { BRICCIA, V. }\end{array}$ & $\begin{array}{l}\text { O desenvolvimento de habilidades de } \\
\text { investigação científica na Educação } \\
\text { Infantil: uma análise a partir de uma } \\
\text { Sequência de Ensino Investigativa. }\end{array}$ & $\begin{array}{l}\text { Faculdade } \\
\text { Montenegro } \\
\text { (FAM)/ } \\
\text { Universidade } \\
\text { Estadual de } \\
\text { Santa Cruz } \\
\text { (UESC) } \\
\end{array}$ & $\mathrm{TC}$ & 2017 \\
\hline 14 & $\begin{array}{l}\text { CHAVES, R. C. de } \\
\text { C. et al. }\end{array}$ & $\begin{array}{l}\text { Educação Ambiental na Educação } \\
\text { Infantil: O Parque Municipal } \\
\text { Germano Augusto Sampaio enquanto } \\
\text { Espaço não Formal de Educação para } \\
\text { a promoção da Alfabetização } \\
\text { Científica. }\end{array}$ & $\begin{array}{l}\text { Universidade } \\
\text { Estadual de } \\
\text { Roraima } \\
\text { (UERR) }\end{array}$ & $\mathrm{TC}$ & 2017 \\
\hline 15 & $\begin{array}{l}\text { AMARAL, S. R. } \\
\text { do; KAUARK, F.S.; } \\
\text { COMARÚ, M. W. }\end{array}$ & $\begin{array}{l}\text { Animação no ensino de ciências: } \\
\text { contribuições para a alfabetização } \\
\text { científica a partir do estudo sobre o ar. }\end{array}$ & $\begin{array}{ll}\text { Instituto } & \text { Federal } \\
\text { do } & \text { Espírito } \\
\text { Santo (Ifes) }\end{array}$ & $\mathrm{TC}$ & 2017 \\
\hline 16 & $\begin{array}{l}\text { UJIIE, N. T.; } \\
\text { PINHEIRO, N. A. } \\
\text { M. }\end{array}$ & 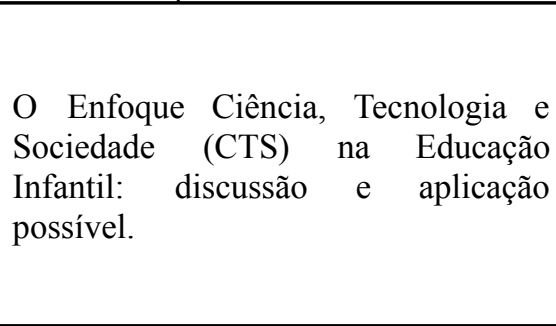 & $\begin{array}{l}\text { Universidade } \\
\text { Estadual do } \\
\text { Paraná } \\
\text { (UNESPAR) / } \\
\text { Universidade } \\
\text { Tecnológica } \\
\text { Federal do } \\
\text { Paraná (UTFPR) }\end{array}$ & $\mathrm{TC}$ & 2017 \\
\hline \multicolumn{6}{|c|}{ Revista Ensaio } \\
\hline $\mathbf{N}^{\mathbf{o}}$ & Autor(es) & Título do trabalho & $\begin{array}{c}\text { IES envolvida } \\
\text { no estudo } \\
\end{array}$ & Tipo & Ano \\
\hline 1 & $\begin{array}{l}\text { MARQUES, A. C. } \\
\text { T. L.; } \\
\text { MARANDINO, M. }\end{array}$ & $\begin{array}{l}\text { Alfabetização Científica e criança: } \\
\text { análise de potencialidades de uma } \\
\text { brinquedoteca. }\end{array}$ & $\begin{array}{l}\text { Instituto Federal } \\
\text { de Educação, } \\
\text { Ciência e } \\
\text { Tecnologia de } \\
\text { São Paulo } \\
\text { (IFSP) / USP }\end{array}$ & A & 2019 \\
\hline
\end{tabular}

Legenda: A: artigo; D: dissertação de mestrado; IES: Instituição de Ensino Superior; T: tese de doutorado; TC: trabalho completo.

Fonte: Elaborado pelos autores, 2021.

A seguir, apresenta-se uma breve caracterização dos trabalhos selecionados na BDTD, no ENPEC e na Revista Ensaio, identificando tendências, localizando lacunas e mapeando a produção da área.

\subsection{Alfabetização Científica na Educação Infantil}

Ao analisar o problema de pesquisa e a metodologia utilizada nos trabalhos na BDTD, verificou-se que um trabalho (CARDOSO, 2017) privilegiou a pesquisa com alunos. Nessa pesquisa, o autor coloca o aluno em evidência e analisa as contribuições de propostas pedagógicas, bem como a sua efetividade na construção de conhecimentos na Educação 
Infantil, dessa forma discutindo a relevância da AC para essa etapa da Educação Básica. Silva (2016) discute elementos da literatura infantil desde a sua gênese até a formação do livro infantil contemporâneo, assim como a relação entre o livro infantil e o Ensino de Ciências na perspectiva da $\mathrm{AC}$, analisando alguns livros infantis.

Em continuidade a essa análise, apenas um trabalho (MENEZES, 2016) contempla as interfaces entre o coletivo dos alunos, professores e pais de alunos. Nele há também um enfoque à Proposta Curricular adotada para a Educação Infantil e o material didático utilizado, analisando perspectivas de Educação Científica nesses documentos. Assim, o artigo promove o debate sobre a relevância e as possibilidades da Educação Científica na infância.

Nos 15 trabalhos do ENPEC analisados, constatou-se que o público priorizado foram os alunos, sendo representados por 11 trabalhos, seguidos por pesquisas direcionadas aos professores com uma representação de dois trabalhos, um trabalho envolvendo alunos e professores e, por fim, dois trabalhos de pesquisas bibliográficas.

Nessa conjuntura, Leporo e Dominguez (2011) se propuseram a verificar os potenciais espaços não formais para a promoção da $\mathrm{AC}$ de alunos do $1^{\circ}$ ano de uma escola pública de Ensino Fundamental. Fagionato-Ruffino e Pierson (2013) identificaram o que crianças de 5 e 6 anos de idade pensam sobre ciência e sobre o trabalho do cientista. Lima e Silva e Capecchi (2015) integraram o aspecto lúdico da brincadeira ao caráter científico investigativo para responder às questões das crianças a partir da observação do fenômeno. Alencar, Terán e Barbosa (2015) procuram compreender o processo de aprendizagem das crianças da pré-escola, usando a vocalização e a música em espaços educativos. No artigo de Pereira, Goulart e Coutinho (2015), há discussões sobre os processos de aprendizagem de ciências por meio de valores e conhecimentos produzidos no universo cultural das próprias crianças.

Paixão, Mandaji e Megid Neto (2015) propõem o desenvolvimento de uma proposta para o ensino de ciências, um tópico de Física relacionado à luz. Marques (2015) analisa a contribuição do trabalho com projetos para o ensino de ciências na Educação Infantil. Utilizando a temática da flutuação, Schneider, Duarte e Silva (2017) analisaram como as crianças constroem concepções em Ciências.

Moraes et al. (2017, p. 1) analisam uma Sequência de Ensino Investigativa que se propõe a "aproximar a cultura da infância com a cultura científica". Chaves et al. (2017) se propõem a conhecer a percepção dos estudantes referente à Educação Ambiental relacionando homem, ambiente, natureza, lixo, consumo consciente e reutilização de objetos, mediatizados a partir do espaço não formal de educação. Já Amaral, Kauark e Comarú (2017) analisam contribuições do uso da animação no ensino de ciências na Educação Infantil para a AC a partir do estudo sobre o ar.

No que corresponde aos artigos direcionados aos professores, Reis e Jannuzzi (2015) apresentam as investigações sobre a construção de conceitos científicos por professores da Educação Infantil. Já o artigo de Amoêdo e Souza (2017) busca compreender como ocorrem o ensino e a aprendizagem com enfoque no Ensino de Ciências de crianças surdas na Educação Infantil. No que tange aos coletivos de alunos e professores, Freitas e Briccia (2017) analisam possibilidades de processos de investigação científica na Educação Infantil a partir de atividades investigativas.

Destacam-se ainda dois trabalhos de revisões bibliográficas. O primeiro é de Maurente e Porciúncula (2013), que verifica como a ciência como saber social e pessoal na Educação Infantil e anos iniciais do Ensino Fundamental tem sido discutida nas produções 
acadêmico-científicas. O outro é de Ujiie e Pinheiro (2017), que discute a temática Ciência, Tecnologia e Sociedade e o enfoque CTS, promovendo aproximação com a Educação Infantil.

\subsection{Propostas de promoção da Alfabetização Científica}

No que se refere às propostas de promoção de $\mathrm{AC}$, os três trabalhos analisados (Quadro 1) na BDTD apresentam estratégias. Cardoso (2017), em sua dissertação de Mestrado, apresenta uma proposta pedagógica norteada pela AC utilizando uma sequência de atividades. Menezes (2016), em sua tese de doutorado, analisa a aplicação do Método Paulo Freire em uma turma Pré-Escolar utilizando a AC como fio condutor. Já a dissertação de mestrado de Silva (2016) destaca a possibilidade de explorar o potencial das obras de literatura infantil para o ensino de ciências e promoção da AC.

Nos trabalhos completos publicados nos anais do ENPEC, oito apresentam estratégias para a promoção da AC. Leporo e Dominguez (2011) destacam o potencial dos espaços não formais para a promoção da AC. Na mesma perspectiva, Chaves et al. (2017) e Alencar, Terán e Barbosa (2015) defendem a utilização dos espaços não formais para o processo do aprender e da AC, pois quebram a rotina da sala de referência na Educação Infantil. Já Lima e Silva e Capecchi (2015) destacam a possibilidade de discussões de cunho científico por meio da brincadeira.

Identificam-se ainda quatro trabalhos, que propõem a promoção da AC por meio do desenvolvimento de atividades diversificadas e lúdicas: a utilização de Ensino Investigativo proposta por Freitas e Briccia (2017) e Moraes et al. (2017); o uso de experimentos para ampliação de conceitos científicos e como disparadores para criação de filmes de animação para a promoção da AC propostos por Amaral, Kauark e Comarú (2017); e as possibilidades do trabalho com projetos no processo de AC propostas por Marques (2015). O único artigo selecionado da Revista Ensaio, de autoria de Marques e Marandino (2019), propõe o uso da brinquedoteca para a promoção da AC.

Assim, cabe destacar a importância dos trabalhos encontrados que contribuem de forma significativa para aproximação das culturas infantis com elementos da cultura científica. Compartilham diferentes experiências e práticas pedagógicas, considerando as especificidades da infância, sugerindo diferentes propostas, que contemplam o brincar livre, o imaginário e a cultura dos pares em diferentes espaços, transformando-os em ambientes educadores.

\section{Considerações Finais}

A construção deste trabalho permitiu visualizar diferentes abordagens de pesquisas sobre a AC na Educação Infantil, bem como uma carência de trabalhos na área em todas as bases consultadas. Desse modo, reiteram-se as considerações iniciais sobre a necessidade de ampliar e aprofundar esse campo de pesquisa, visto que a Educação Infantil se encontra ainda em processo de consolidação pedagógica para o cumprimento da Lei n. ${ }^{\circ}$ 12.796/2013 (BRASIL, 2013), que trata da obrigatoriedade da educação a partir 4 anos de idade. A partir dessa demanda, é necessário repensar o acesso, a permanência e a qualidade de ensino oferecido.

O mapeamento que este estudo propôs evidenciou pouca incidência de trabalhos, porém as pesquisas realizadas mostraram inúmeras potencialidades para a promoção da $\mathrm{AC}$ na Educação Infantil, que são sintetizadas a seguir: 
a) utilização dos espaços não formais para o processo do aprender e da AC;

b) aplicação de atividades lúdicas para promoção da AC;

c) uso de obras de literatura infantil para o ensino de ciências e promoção da AC;

d) reflexão e ação sobre currículo, metodologias e possibilidades para a promoção da $\mathrm{AC}$;

e) promoção da $\mathrm{AC}$ por meio do desenvolvimento de atividades diversificadas, como brincadeiras, brinquedoteca e uso de animações;

f) utilização de sequências didáticas bem estruturadas e ensino por projetos como agentes potenciais para o desenvolvimento do processo de AC.

Sobretudo, cabe mencionar que os trabalhos apresentaram variadas experiências de interação e conhecimento. Verificamos diversas possibilidades de desenvolvimento de propostas por meio do acesso aos conceitos científicos formulados com base em ações efetivas, considerando os pressupostos da $\mathrm{AC}$, os documentos oficiais de orientação e o atendimento às especificidades e necessidades das crianças da Educação Infantil.

As práticas relatadas em sua maioria estimulavam o desenvolvimento da autonomia e do protagonismo infantil, oportunizando o exercício dos direitos como cidadãos críticos e reflexivos, que constroem hipóteses, buscam soluções e apontam caminhos para situações e problemáticas propostas em seu cotidiano.

Por fim, considerando as pesquisas analisadas que envolviam os professores da Educação Infantil, evidenciou-se uma escassez ainda maior de trabalhos, já que focavam a pesquisa em conjunto com os alunos, mas priorizavam as discussões para a promoção da AC.

Assim, observa-se a importância do debate sobre AC com professores e gestores da Educação Infantil para que a abordagem científica faça parte dos currículos e, principalmente, para que seja efetiva na prática docente. Contudo, considera-se pertinente a implementação da AC nos cursos de formação inicial e continuada de professores, a fim de promover ações educativas que contribuam para a formação cidadã, para a tomada de decisões e para a compreensão das relações da ciência e da tecnologia na sociedade em que alunos e professores estão inseridos.

\section{Referências}

ALENCAR, R. N. B. de; TERÁN, A. F; BARBOSA, I. dos S. O processo de aprendizagem das crianças da pré-escola usando o "Peixe-boi-da-Amazônia" (Trichechus inunguis). In: ENCONTRO NACIONAL DE PESQUISA EM EDUCAÇÃO EM CIÊNCIAS, 10., 2015, Águas de Lindóia. Anais [...]. Águas de Lindóia: ENPEC, 2015. p. 1-9. Disponível em: http://www.abrapecnet.org.br/enpec/x-enpec/anais2015/resumos/R1187-1.PDF. Acesso em: 08 jun. 2019.

AMARAL, S. R. do; KAUARK, F. da S.; COMARÚ, M. W. Animação no ensino de ciências: contribuições para a alfabetização científica a partir do estudo sobre o ar. In: ENCONTRO NACIONAL DE PESQUISA EM EDUCAÇÃO EM CIÊNCIAS ENPEC, 11., 2017, Florianópolis. Anais [...]. Florianópolis: ENPEC, 2017. p. 1-10. Disponível em: http://www.abrapecnet.org.br/enpec/xi-enpec/anais/resumos/R2562-1.pdf. Acesso em: 12 jun. 2019.

AMOÊDO, F. K. de F.; SOUZA, J. C. R. de. Educação infantil e o diálogo de comunicar ciências às crianças surdas na cidade de Parintins-AM. In: ENCONTRO NACIONAL DE 
PESQUISA EM EDUCAÇÃO EM CIÊNCIAS ENPEC, 11., 2017, Florianópolis. Anais [...]. Florianópolis: ENPEC, 2017. p. 1-11. Disponível em:

http://www.abrapecnet.org.br/enpec/xi-enpec/anais/resumos/R0732-1.pdf. Acesso em: 12 jun. 2019.

AULER, D.; DELIZOICOV, D. Alfabetização Científico-Tecnológica Para Quê? ENSAIO:

Pesquisa em Educação em Ciências, Belo Horizonte, v. 03, n. 02, p. 122-134, jul-dez. 2001.

BARDIN, L. Análise de conteúdo. São Paulo: Edições 70, 2011.

BETTANIN, E. As Ilhas de Racionalidade na promoção dos objetivos da Alfabetização Científica e Técnica. 2003. Dissertação (Mestrado em Educação) - Universidade Federal de Santa Catarina, Florianópolis, 2003.

BIBLIOTECA Digital Brasileira de Teses e Dissertações (BDTD). Página inicial. Disponível em: http://bdtd.ibict.br/vufind/. Acesso em: 06 jun. 2019.

BRANDI, A. T. E.; GURGEL, C. M. do A. A alfabetização científica e o processo de ler e escrever em séries iniciais: emergências de um estudo de investigação-ação. Ciência \&

Educação, Bauru, v. 8, n. 1, p. 113-125, 2002.

BRASIL. Emenda Constitucional $n^{\circ} 59$ de 11 de novembro de 2009. Acrescenta $\S 3^{\circ}$ ao art. 76 do Ato das Disposições Constitucionais Transitórias para reduzir, anualmente, a partir do exercício de 2009. Diário Oficial da União: Brasília, p. 8, 12 nov. 2009.

BRASIL. Lei $\mathbf{n}^{0}$ 12.796, de 04 de abril de 2013. Altera a Lei ${ }^{\circ} 9.394$, de 20 de dezembro de 1996, que estabelece as diretrizes e bases da educação nacional, para dispor sobre a formação dos profissionais da educação e dar outras providências. Brasília: MEC, 2013. Disponível em: http://www.planalto.gov.br/ccivil_03/_Ato2011-2014/2013/Lei/L12796.htm. Acesso em: 06 jun. 2019.

BRASIL. Lei $\mathbf{N}^{\circ}$ 9.394, de 20 de dezembro de 1996. Estabelece as diretrizes e bases da educação nacional. Brasília: MEC, 1996. Disponível em:

http://www.planalto.gov.br/ccivil_03/leis/19394.htm. Acesso em: 06 jun. 2019.

CARDOSO, R. A. P. Alfabetização científica na pré-escola: ações em busca de transformações para uma educação sustentável. 2017. Dissertação (Mestrado em Ensino de Ciências Naturais e Matemática) - Universidade Regional de Blumenau, Blumenau, 2017. 111f. Disponível em: http://www.bc.furb.br/docs/DS/2017/363165_1_1.pdf. Acesso em: 06 jun. 2019.

CARVAlHO, A. M. P. de. Formação de professores de Ciências - Ana Maria Pessoa de Carvalho. 2012. 1 vídeo (16min47s). Disponível em:

http://www.youtube.com/watch?v=IMyfqxACezE. Acesso em: 26 dez. 2019.

CARVALHO, A. M. P. de; TINOCO, S. C. O Ensino de Ciências como 'enculturação'. In: CATANI, D. B.; VICENTINI, P. P. (org.). Formação e autoformação: saberes e práticas nas experiências dos professores. São Paulo: Escrituras, 2006. 
CHASSOT, A. Alfabetização científica: questões e desafios para a educação. Ijuí: Unijuí, 2000. $434 \mathrm{p}$.

CHAVES, R. C. de C. et al. Educação ambiental na educação infantil: o Parque Municipal Germano Augusto Sampaio enquanto Espaço não Formal de Educação para a promoção da Alfabetização Científica. In: ENCONTRO NACIONAL DE PESQUISA EM EDUCAÇÃO EM CIÊNCIAS ENPEC, 11., 2017, Florianópolis. Anais [...]. Florianópolis: ENPEC, 2017. p. 1-12. Disponível em:

http://www.abrapecnet.org.br/enpec/xi-enpec/anais/resumos/R0136-1.pdf. Acesso em: 12 jun. 2019.

DELIZOICOV, D; ANGOTTI, J. A; PERnAMBUCO, M. M. C. A. Metodologia do ensino de ciências. São Paulo: Cortez, 2011.

ENCONTRO Nacional de Pesquisa em Educação em Ciências (ENPEC). ENPECs

Anteriores. Disponível em: http://abrapecnet.org.br/wordpress/pt/enpecs-anteriores/. Acesso em: 06 jun. 2019.

ENSAIO - Pesquisa em Educação em Ciências. Edições anteriores. Disponível em: https://periodicos.ufmg.br/index.php/ensaio/issue/archive. Acesso em: 06 jun. 2019.

FAGIONATO-RUFFINO, S.; PIERSON, A. H. C. Cientista tem o cabelo arrepiado, constrói robôs e polvos gigantes - ideias de crianças de 5 e 6 anos sobre a ciência e o trabalho do cientista. In: ENCONTRO NACIONAL DE PESQUISA EM EDUCAÇÃO EM CIÊNCIAS, 9., 2013, Águas de Lindóia. Anais [...]. Águas de Lindóia: ENPEC, 2013. p. 1-8. Disponível em: http://abrapecnet.org.br/atas_enpec/ixenpec/atas/resumos

/R0927-1.pdf. Acesso em: 10 jun. 2019.

FERNANDES, R. C. A.; MEGID NETO, J. Características e tendências das dissertações e teses brasileiras sobre práticas de ensino de ciências nos anos iniciais escolares (1972-2011). Revista Interacções, Santarém, v. 11, n. 39, p. 540-551, 2015. Disponível em: https://revistas.rcaap.pt/interaccoes/article/view/8757/6315. Acesso em: 06 jun. 2019.

FERREIRA, N. S. de A. As pesquisas denominadas "Estado da Arte”. Educação \& Sociedade, Campinas, v. 23, n. 79, p. 257-272, 2002. Disponível em: https://doi.org/10.1590/S0101-73302002000300013. Acesso em: 06 jun. 2019.

FOUREZ, G. Alfabetización científica y tecnologica. Acerca de las finalidades de la enseñanza de las ciencias. Buenos Aires: Ediciones Colihue, 1997.

FREITAS, A. C. S.; BRICCIA, V. O desenvolvimento de habilidades de investigação científica na Educação Infantil: uma análise a partir de uma Sequência de Ensino Investigativa. In: ENCONTRO NACIONAL DE PESQUISA EM EDUCAÇÃO EM CIÊNCIAS, 11., 2017, Florianópolis. Anais [...]. Florianópolis: ENPEC, 2017. p. 1-8. Disponível em: http://www.abrapecnet.org.br/enpec/xi-enpec/anais/resumos/R1909-1.pdf. Acesso em: 11 jun. 2019.

HAZEN, R. M.; TREFIL, J. Saber ciência. São Paulo: Cultura Editores Associados, 1995. 
KLEIMAN, A. Modelos de Letramento e as Práticas de Alfabetização na Escola. In: KLEIMAN, A. (org.), Os Significados do Letramento: Uma nova perspectiva sobre a prática social da escrita. Campinas: Mercado das Letras, 1995.

LEAL, M. C.; GOUVÊA, G. Narrativa, mito, ciência e tecnologia: o ensino da ciência na escola e no museu. ENSAIO: Pesquisa em Educação em Ciências, Belo Horizonte, v. 2, n. 1, p. 5-33, 2000.

LEPORO, N.; DOMINGUEZ, C. R. C. Alfabetização científica na educação infantil: quando os pequenos visitam o museu de ciências. In: ENCONTRO NACIONAL DE PESQUISA EM EDUCAÇÃO EM CIÊNCIAS, 8., 2011, Campinas. Anais [...]. Campinas: ENPEC, 2011. p. 1-11. Disponível em: http://abrapecnet.org.br/atas_enpec/viiienpec/ resumos/R0890-2.pdf. Acesso em: 06 jun. 2019.

LIMA E SILVA, V. M. de; CAPECCHI, M. C. V. de. Ciências na educação infantil: uma abordagem investigativa para brincadeira com bolinhas de sabão. In: ENCONTRO NACIONAL DE PESQUISA EM EDUCAÇÃO EM CIÊNCIAS, 10., 2015, Águas de Lindóia. Anais [...]. Águas de Lindóia: ENPEC, 2015. p. 1-8. Disponível em: http://www.abrapecnet.org.br/enpec/x-enpec/anais2015/resumos/R1700-1.PDF. Acesso em: 06 jun. 2019.

LORENZETTI, L. Alfabetização científica nas séries iniciais. 2000. Dissertação (Mestrado em Educação) - Universidade Federal de Santa Catarina, Florianópolis, 2000.

LORENZETTI, L. A promoção e avaliação da alfabetização científica nos anos iniciais. In: VIVEIRO, A. A.; MEGID NETO, J. (org.). Ensino de ciências para crianças: fundamentos, práticas e formação de professores. Itapetininga: Edições Hipótese, 2020.

LORENZETTI, L.; DELIZOICOV, D. Alfabetização científica no contexto das séries iniciais. ENSAIO - Pesquisa em Educação em Ciências, Belo Horizonte, v. 3, n. 1, p. 45-61, jun. 2001. DOI https://doi.org/10.1590/1983-21172001030104. Acesso em: 06 jun. 2019.

MAMEDE, M.; ZIMMERMANN, E. Letramento científico e CTS na formação de professores para o ensino de física. In: SIMPÓSIO NACIONAL DE ENSINO DE FÍSICA, 16., 2005, Rio de Janeiro. Anais [...]. Disponível em:

http://www.sbf1.sbfisica.org.br/eventos/snef/xvi/cd/resumos/T0264-1.pdf. Acesso em: 16 maio 2021.

MARQUES, A. C. T. L. Ciências na Educação Infantil: uma reflexão a partir do trabalho com projetos. In: ENCONTRO NACIONAL DE PESQUISA EM EDUCAÇÃO EM CIÊNCIAS, 10., 2015, Águas de Lindóia. Anais [...]. Águas de Lindóia: ENPEC, 2015. p. 1-8. Disponível em: http://www.abrapecnet.org.br/enpec/x-enpec/anais2015/resumos/R0114-1.PDF. Acesso em: 09 jun. 2019.

MARQUES, A. C. T. L.; MARANDINO, M. Alfabetização científica, criança e espaços de educação não formal: diálogos possíveis. Educação e Pesquisa, São Paulo, v. 44, p. 1-19, 2018. DOI https://doi.org/10.1590/s1678-4634201712170831. Acesso em: 06 jun. 2019. 
MARQUES, A. C. T. L.; MARANDINO, M. Alfabetização científica e criança: análise de potencialidades de uma brinquedoteca. Ensaio Pesquisa em Educação em Ciências, Belo Horizonte, v. 21, 2019. DOI https://doi.org/10.1590/1983-21172019210102. Acesso em: 06 jun. 2019.

MAURENTE, V. M. M.; PORCIÚNCULA, L. de O. Um mergulho pelas atas do ENPEC: indo ao encontro da ciência na educação infantil e nos anos iniciais. In: ENCONTRO NACIONAL DE PESQUISA EM EDUCAÇÃO EM CIÊNCIAS, 9., 2013, Águas de Lindóia. Anais [...]. Águas de Lindóia: ENPEC, 2013. p. 1-8. Disponível em: http://abrapecnet.org.br/atas_enpec/ixenpec/atas/resumos/R1580-1.pdf. Acesso em: 06 jun. 2019.

MEGID NETO, J. Origens e Desenvolvimento do Campo de Pesquisa em Educação em Ciências no Brasil. In: NARDI, R.; GONÇALVES, T. V. O. (org.). Pós-Graduação em Ensino de Ciências e Matemática no Brasil: memórias, programas e consolidação da pesquisa na área. São Paulo: Livraria da Física, 2014. p. 98-139.

MENEZES, M. C. F. de. Um diálogo entre a pedagogia freireana e a educação científica na educação infantil. 2016. Tese (Doutorado em Ensino, Filosofia e História das Ciências.) -Universidade Estadual de Feira de Santana, Salvador, 2016. Disponível em:

https://ppgefhc.ufba.br/sites/ppgefhc.ufba.br/files/maria_cilene_freire_-_tese.pdf. Acesso em: 06 jun. 2019.

MILARÉ, T.; RICHETTI, G. P.; ALVES FILHO, J. de P. Alfabetização científica no ensino de Química: uma análise dos temas da seção Química e Sociedade da Revista Química Nova na Escola. Química Nova na Escola, São Paulo, v. 31, n. 3, p. 165-171, 2009.

MORAES, T. S. V. de et al. O desenvolvimento de ações de Investigação Científica com crianças da Educação Infantil. In: ENCONTRO NACIONAL DE PESQUISA EM

EDUCAÇÃO EM CIÊNCIAS ENPEC, 11., 2017, Florianópolis. Anais [...]. Florianópolis: ENPEC, 2017. p. 1-11. Disponível em:

http://www.abrapecnet.org.br/enpec/xi-enpec/anais/resumos/R1559-1.pdf. Acesso em: 11 jun. 2019.

MORTIMER, E. F.; MACHADO, A. H. A linguagem em uma aula de ciências. Presença Pedagógica, Belo Horizonte, v. 2, n. 11, p. 49-57, 1996.

MOZENA, E. R.; OSTERMANN, F. Uma revisão bibliográfica sobre a interdisciplinaridade no ensino das ciências da natureza. ENSAIO: Pesquisa em Educação em Ciências, Belo Horizonte, v. 16, n. 02, p. 185-206, maio-ago. 2014. Disponível em:

http://dx.doi.org/10.1590/1983-21172014160210. Acesso em: 16 maio 2021.

PAIXÃO, F. J. da; MANDAJI, K. C.; MEGID NETO, J. Brincando com a luz: Ciência na pré-escola. In: ENCONTRO NACIONAL DE PESQUISA EM EDUCAÇÃO EM

CIÊNCIAS, 10., 2015, Águas de Lindóia. Anais [...]. Águas de Lindóia: ENPEC, 2015. p. 1-8. Disponível em:

http://www.abrapecnet.org.br/enpec/x-enpec/anais2015/resumos/R1212-1.PDF. Acesso em: 09 jun. 2019. 
PAVÃO, A. C. Ensinar Ciências fazendo ciência. In: PAVÃO, A. C. (org.). O livro didático em questão. Brasília: MEC, 2006.

PEREIRA, A. F.; GOULART, M. I. M.; COUTINHO, F. Â. Aprendizagem de ciências na educação infantil enquanto participação em um campo de prática: primeiras aproximações. In: ENCONTRO NACIONAL DE PESQUISA EM EDUCAÇÃO EM CIÊNCIAS, 10., 2015, Águas de Lindóia. Anais [...]. Águas de Lindóia: ENPEC, 2015. p. 1-8. Disponível em: http://www.abrapecnet.org.br/enpec/x-enpec/anais2015/lista_area_16.htm. Acesso em: 08 jun. 2019.

REIS, A. C.; JANNUZZI, C. M. L. Ensino de ciências para professores da educação infantil. In: ENCONTRO NACIONAL DE PESQUISA EM EDUCAÇÃO EM CIÊNCIAS, 10., 2015, Águas de Lindóia. Anais [...]. Águas de Lindóia: ENPEC, 2015. p. 1-7. Disponível em: http://www.abrapecnet.org.br/enpec/x-enpec/anais2015/resumos/R2241-1.PDF. Acesso em: 06 jun. 2019.

ROMANOWSKI, J. P.; ENS, R. T. As pesquisas denominadas do tipo "Estado da Arte" em educação. Diálogo Educacional, Curitiba, v. 6, n. 19, p. 37-50, 2006. Disponível em: https://periodicos.pucpr.br/index.php/dialogoeducacional/article/view/24176/22872. Acesso em: 06 jun. 2019.

SANTOS, W. L. P. dos; MORTIMER, E. F. Tomada de Decisão para Ação Social Responsável no Ensino de Ciências. Ciência \& Educação, Bauru, v. 7, n. 1, p. 95-111, 2001.

SASSERON, L. H.; CARVALHO, A. P de. Almejando a alfabetização científica no ensino fundamental: a proposição e a procura de indicadores do processo. Investigações em Ensino de Ciências, Porto Alegre, v. 13, n. 3, p. 333-352, 2008.

SASSERON, L. H.; CARVALHO, A. M. P. de. Alfabetização Científica: uma revisão bibliográfica. Investigações em Ensino de Ciências, Porto Alegre, v. 16, n. 1, p. 59-77, 2011.

SCHNEIDER, Mariângela Costa. O protagonismo infantil e as estratégias de ensino que favorecem em uma turma da educação infantil. 2015. Dissertação (Mestrado em Ensino) Universidade do Vale do Taquari, Lajeado, 2015. Disponível em: http://hdl.handle.net/10737/1050. Acesso em: 10 jun. 2019.

SCHNEIDER, M. C.; DUARTE, M. Cr.; SILVA, L. H. de A. Ciências na Educação Infantil: explorando a flutuabilidade na Pré-escola. In: ENCONTRO NACIONAL DE PESQUISA EM EDUCAÇÃO EM CIÊNCIAS, 11., 2017, Florianópolis. Anais [...]. Florianópolis: ENPEC, 2017. p. 1-8. Disponível em:

http://www.abrapecnet.org.br/enpec/xi-enpec/anais/resumos/R1792-1.pdf. Acesso em: 10 jun. 2019.

SILVA, T. P. da. Mamãe galinha, menina joaninha: representações dos animais no livro infantil e suas possibilidades na educação científica. Dissertação (Mestrado em Educação) -Universidade de São Paulo, São Paulo, 2016. Disponível em:

http://dx.doi.org/10.11606/D.48.2016.tde-06102016-153955. Acesso em: 06 jun. 2019.

SOARES, M. Letramento: um tema em três gêneros. Belo Horizonte: Autêntica, 1998. 
TENREIRO-VIEIRA, C.; VIEIRA, R. M. Educação em ciências e em matemática numa perspectiva de literacia: desenvolvimento de materiais didáticos com orientação CTS/ pensamento crítico (PC). In: SANTOS, W. L. P. dos; AULER, D. (org.). CTS e educaçãa científica: desafios, tendências e resultados de pesquisas. Brasília: Universidade de Brasília, 2011. p. 417-438.

UJIIE, N. T.; PINHEIRO, N. A. M. O Enfoque Ciência, Tecnologia e Sociedade (CTS) na Educação Infantil: discussão e aplicação possível. In: ENCONTRO NACIONAL DE PESQUISA EM EDUCAÇÃO EM CIÊNCIAS, 11., 2017, Florianópolis. Anais [...]. Florianópolis: ENPEC, 2017. p. 1-11. Disponível em:

http://www.abrapecnet.org.br/enpec/xi-enpec/anais/resumos/R1772-1.pdf. Acesso em: 12 jun. 2019.

VIECHENESKI, J. P.; LORENZETTI, L.; CARLETTO, M. R. A alfabetização científica nos anos iniciais: uma análise dos trabalhos apresentados nos ENPECs. In: ENCONTRO NACIONAL DE PESQUISA EM EDUCAÇÃO EM CIÊNCIAS, 10., 2015, Águas de Lindóia. Anais [...]. Águas de Lindóia: ENPEC, 2015. p. 1-9. Disponível em: http://www.abrapecnet.org.br/enpec/x-enpec/anais2015/resumos/R0409-1.PDF. Acesso em: 02 jun. 2019.

Recebido em janeiro de 2021.

Aprovado em maio de 2021. 